\title{
STABILITY OF LARGE AMPLITUDE FORCED MOTION OF A SIMPLY SUPPORTED BEAM
}

\author{
JoE G. EISLEY* and JAMES A. BENNETT'
}

The University of Michigan, Ann Arbor, Michigan

\begin{abstract}
The large amplitude steady state forced motion of a simply supported beam with ends restrained to remain a fixed distance apart is represented by a series of linear normal modes. The validity of the assumption of single mode response is examined by investigating the stability of the unforced modes when a single mode is forced. The equations include the effects of an initial axial load and numerical examples are presented for axial loads in both the pre- and post-buckling regions. It is concluded that the approximation of single mode response is not always valid because of the possible instability of higher modes.
\end{abstract}

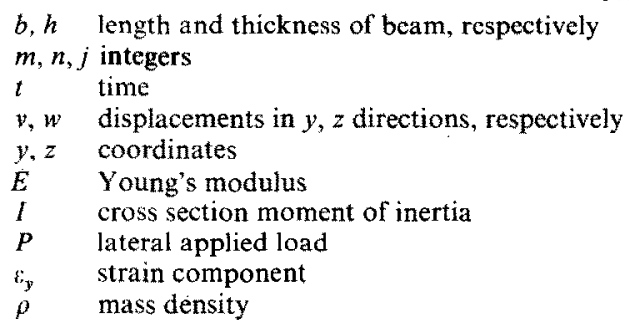

\section{NOTATION}

Other symbols are defined in the text.

\section{INTRODUCTION}

WHEN a beam with ends restrained to remain a fixed distance apart vibrates laterally there is stretching of the median line. This effect may be accounted for in the strain displacement relation by taking

$$
\epsilon_{y}=v_{, y}+\frac{1}{2}\left(w_{, y}\right)^{2}
$$

where a comma denotes differentiation with respect to the subscript.

If the other usual assumptions of simple beam theory are retained the following equation results for a beam of unit width

$$
\rho h w_{, t t}+\left(E I w_{, y y}\right)_{, y y}-\frac{E h}{b}\left[v_{0}+\frac{1}{2} \int_{0}^{b}\left(w_{, y}\right)^{2} \mathrm{~d} y\right] w_{, y y}=P(y, t)
$$

where $v_{0}$ represents an initial axial displacement measured from the unstressed state. The derivation of this equation is done in detail by Burgreen [1] and McDonald [2].

* Professor of Aerospace Engineering.

$\dagger$ Formerly Research Assistant, Department of Aerospace Engineering. Presently Assistant Professor of Aeronautical and Astronautical Engineering, University of Illinois, Urbana, Illinois. 
The solution of this equation has been examined by several investigators by expanding the deflection $w$ in a series of linear normal modes of vibration of the beam to obtain a set of ordinary differential equations which describe the motion. An extensive bibliography is given by Eisley [3]. Several papers report on various aspects of single mode response. Among them are papers by Burgreen [1], Mettler [4], and Eisley [5]. An investigation of the infinite degree of freedom free motion of a simply supported beam is reported by McDonald [2].

In the following paragraphs the validity of the assumption of a single mode response is examined by forcing one mode and determining the stability of the other modes. The equations include the effects of an initial axial load and numerical examples are presented for a range of axial loads in both the pre-buckling and post-buckling regions.

This investigation wás aided by the work of Henry and Tobias [6], and Gilchrist [7], Williams and Tobias [8], and Efstathiades and Williams [9] on problems of related interest.

\section{METHOD OF SOLUTION}

For a simply supported beam let

$$
w(y)=b \sum_{n=1}^{\infty} \xi_{n}(\tau) \sin \frac{n \pi y}{b}
$$

where the $\xi_{n}{ }^{\prime} s$ are generalized coordinates and $\tau$ is a nondimensional time

$$
\tau=(E / \rho)^{\frac{1}{2}} \frac{t}{b} .
$$

The following set of ordinary non-linear differential equations are obtained by Galerkin's method

$$
\xi_{n, \tau \tau}+p_{n} \xi_{n}+q_{n}\left(\sum_{m=1}^{\infty} m^{2} \xi_{m}^{2}\right) \xi_{n}=Q_{n}
$$

where

$$
\begin{gathered}
p_{n}=\frac{\pi^{4}}{12} \alpha^{2} n^{2}\left(n^{2}-\lambda\right) \quad q_{n}=\frac{n^{2} \pi^{4}}{4} \\
Q_{n}=\frac{2}{E h} \int_{0}^{b} P(y, t) \sin \frac{n \pi y}{b} \mathrm{~d} y
\end{gathered}
$$

and

$$
\alpha=\frac{h}{b} \quad \lambda=\frac{v_{0}}{v_{\mathrm{o}_{c r}}}
$$

where $v_{0_{c r}}$ is the end displacement at the buckling load. The buckling load is reached at $\lambda=1$. 
Steady state solutions of the form

$$
\bar{\xi}_{n}=A_{n} \cos \left(\beta_{n} \omega \tau+\phi_{n}\right)
$$

where $A_{n}$ is the amplitude, $\beta_{n}$ is an integer and $\phi_{n}$ is the phase angle are sought. The method of harmonic balance is used to determine amplitude-frequency relations.

Except for McDonald [2] who considered only free motion with no initial axial load, efforts to obtain a solution for the steady state motion have been limited to single mode response. The stability of a single mode response is now examined.

\section{STABILITY OF SINGLE MODF. RESPONSE}

Consider the special case of harmonic forcing applied to just one of Eq. (5) or

$$
\begin{aligned}
Q_{n} & =Q_{j}=B_{j} \cos \omega \tau & & n=j \\
& =0 & & n \neq j .
\end{aligned}
$$

A possible approximate solution is

$$
\begin{aligned}
\bar{\xi}_{n}(\tau) & =\bar{\xi}_{j}=A_{j} \cos \omega \tau & & n=j \\
& =0 & & n \neq j .
\end{aligned}
$$

The resulting amplitude frequency relation is

$$
\omega^{2}=p_{j}+\frac{3}{4} j^{2} A_{j}^{2} q_{j}-\frac{B_{j}}{A_{j}}
$$

This solution represents a single mode response. In the linear case there is no coupling of the governing equations and so a single mode response is always possible. In the nonlinear case, however, the equations are coupled through the non-linear terms so that excitation of one generalized coordinate may result in excitation of other coordinates. If this should happen the approximation of single mode response or, in general, truncation of the assumed series for the deflection may not be valid.

To determine stability let

$$
\xi_{n}(\tau)=\bar{\xi}_{n}(\tau)+\gamma_{n}(\tau)
$$

where $\gamma_{n}$ is a small quantity. Note that $\vec{\xi}_{n}=0$ when $n \neq j$. When only first order terms in $\gamma_{n}$ are retained the following equations are ohtained

$$
\begin{array}{ll}
\gamma_{j, \tau \tau}+\left(p_{j}+3 j^{2} q_{j} \bar{\xi}_{j}^{2}\right) \gamma_{j}=0 & n=j \\
\gamma_{n_{, \tau \tau}}+\left(p_{n}+j^{2} q_{n} \bar{\xi}_{j}^{2}\right) \gamma_{n}=0 & n \neq j
\end{array}
$$

Each of these equations is a Mathieu equation and may be put in the standard form

$$
\gamma_{n, z z}+\left(\delta_{n}+\epsilon_{n} \cos z\right) \gamma_{n}=0
$$

where

$$
z=2 \omega \tau
$$


and

$$
\begin{aligned}
& \delta_{j}=\begin{array}{c}
p_{j}+3 j^{2} q_{j} A_{j}^{2} / 2 \\
4 \omega^{2}
\end{array} \quad \epsilon_{j}=\frac{3 j^{2} q_{j} A_{j}^{2}}{8 \omega^{2}} \quad n=j \\
& \delta_{n}=\frac{p_{n}+j^{2} q_{n} A_{n}^{2} / 2}{4 \omega^{2}} \quad c_{n}=\frac{j^{2} q_{n} A_{n}^{2}}{8 \omega^{2}} \quad n \neq j .
\end{aligned}
$$

The stability properties of this equation are well known $[10,11]$, and are usually presented in terms of $\delta$ and $\epsilon$ in graphical form as shown in Fig. 1(a). A stability analysis similar to the one considered here is reported by Henry and Tobias [6]. In the figure the shaded regions are stable. For a given beam the stability boundaries may be found in terms of amplitude and frequency and superposed as a response curve plot.

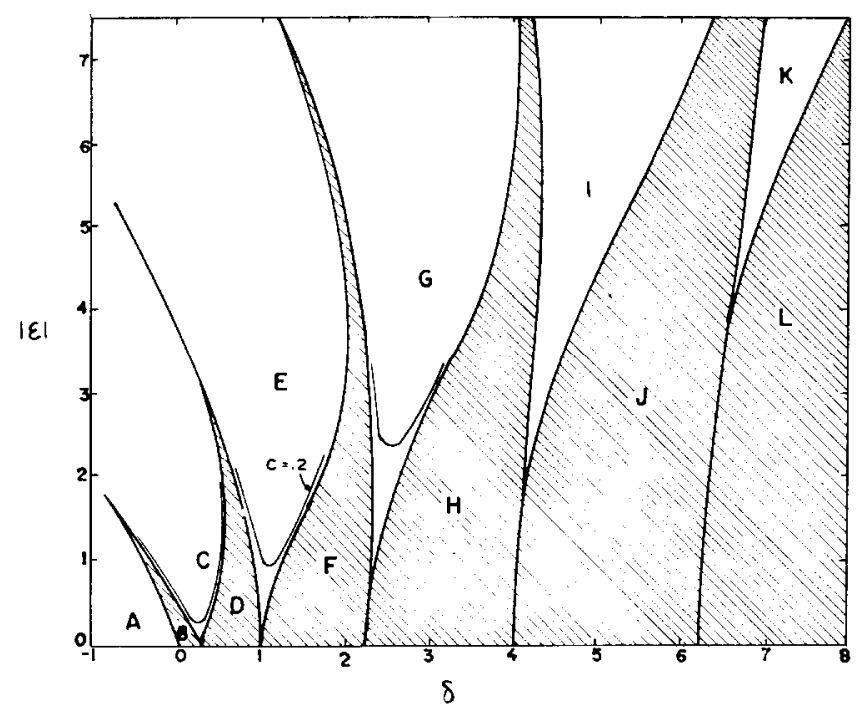

FIG. 1(a). Mathieu equation stability boundaries.

The single term harmonic balance method assumes that the effect of higher order harmonics is negligible. Analog computer results indicate that for the range of values considered the response did not contain any higher harmonics. The Mathieu equation may also be solved using a single term harmonic balance method. If this is done the boundaries are straight lines as shown in Fig. 1(b). Note that only the first instability region shown in Fig. 1(a) is retained by the approximate solution shown in Figure 1(b). Analog computer solutions show, however, that the higher order instabilities, ruled out by the approximate solution do, in fact, exist. This leads to the conclusion that the approximate solution of the Mathieu equation is not sufficient. The analog computer solutions suggest that the full boundaries shown in Fig. 1(a) are more accurate statements of the stability regions. Some of these results are shown in the figures which follow. 
The approximate stability boundaries for the first region of instability are quite close to the exact boundaries, closer than the analog computer solutions were able to distinguish stability boundaries. The approximate boundaries for the first mode coincide with the free vibration response line, and there are physical arguments to support that this should be so. In the figures which follow the approximate boundaries are used for the first region

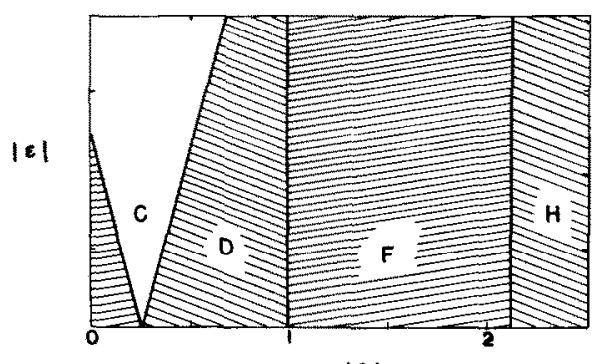

181

FiG. 1(b). Approximate Mathieu stability boundiries.

and the exact values for all other regions. This is justified by the analog computer solutions which show that the approximate boundaries for the higher order regions are inadequate.

The stability properties for the case $n=j=l$ are shown in Fig. 2 for a beam with $\alpha=0.005$ and $\lambda=0$. The shaded lines are stability boundaries with the shading on the stable side. Thus regions $B, D, F$ are stable and $C, E$ are unstable. Those boundaries which originate at $T_{0} / T<1.0$ correspond to ultraharmonics, where the response frequency is some integer multiple of the forcing frequency [11]. The boundary which originates at $T_{0} / T=1.0$ is that for the familiar jump instability.

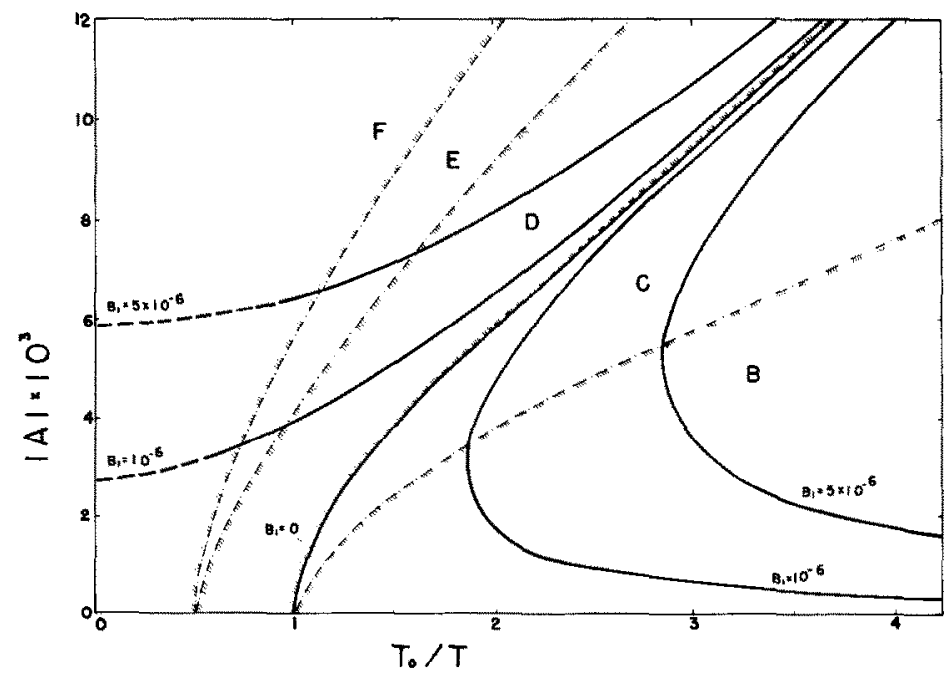

FiG. 2. Stability regions for single (first) mode response. $\lambda=0$. 
The case $n=2, j=1$ is shown in Fig. 3. This is an instability of the second mode which is initially at rest. The stable areas are indicated by shading between the lines. Analog computer solutions are shown. Note that the second mode instability which occurs in region $E$ would not be predicted by the approximate solution to the Mathieu equation because that region reduces to a single line. Typical analog computer traces are shown in Fig. 6.

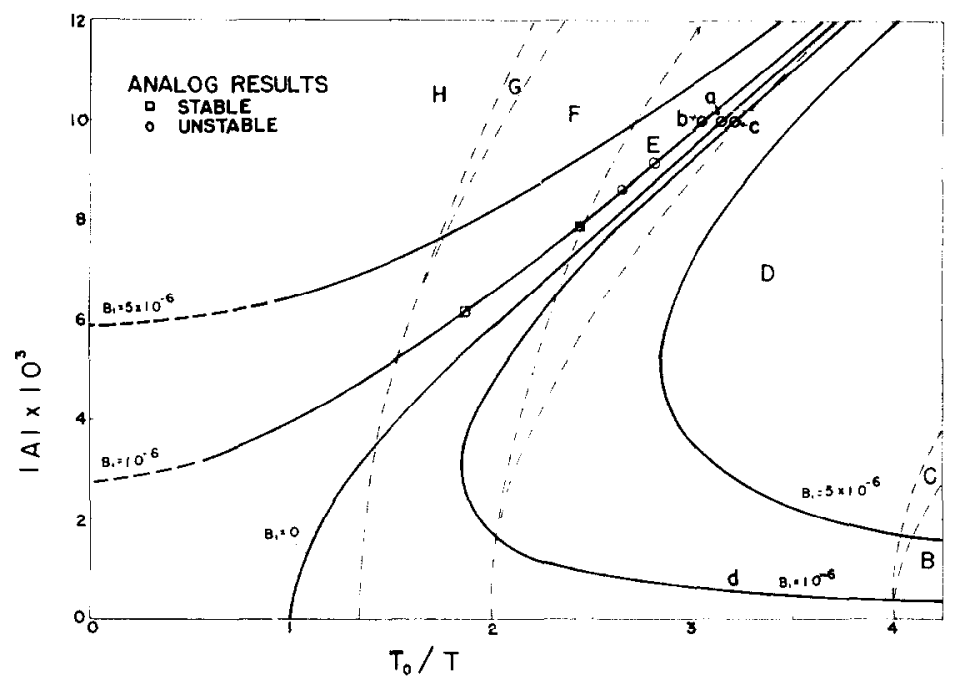

FIG. 3. Stability regions for the second mode with the first mode forced. $\lambda=0$.

The complete stability diagram is given in Fig. 4(a). For clarity only one of the ultraharmonic regions and only two of the second mode instability regions are shown. Note that there are areas in which the first mode alone is stable, but the addition of a second mode indicates an instability. In these cases the assumption of a single mode response is no longer valid. Combined stability diagrams for other values of $\lambda$ are given in Figs. 4(b), and (4c).

Similar results are shown in Figs. 5(a)-(c) for second mode excitation with all other modes initially at rest. In Fig. 5(a) the shaded lines define the boundaries of stability of the second mode response and the other lines show stability boundaries for the first mode initially at rest. In the shaded regions the second mode response is stable but the first mode is not stable at rest. In Fig. 5(b) second and third mode stability boundaries are shown for the same response curve as in Fig. 5(a). Other values of $\lambda$ are shown in Figs. 5(c) and (d). Since for second mode response it is the third mode which is most likely to be coupled only stability boundaries for the second and third modes are shown in Figs. 5(c), and (d).

No further numerical results will be shown for single mode response. The pattern that has developed is that if one mode is excited the next higher mode at rest may also be excited under the right circumstances. There are also narrow regions in which lower modes and higher modes may be excited. It may be argued that a small amount of damping will eliminate the instability of these additional modes. Curves are shown in Fig. (1) to illustrate that a small amount of damping significantly increases the stable portions on the Mathieu stability chart. These curves correspond to $c=0.2$ when the Mathieu equation is modified 
as follows

$$
\gamma_{n, z z}+2 c \gamma_{n, z}+\left(\delta_{n}+\epsilon_{n} \cos z\right) \gamma_{n}=0
$$

and the portion below these curves are the stable regions.

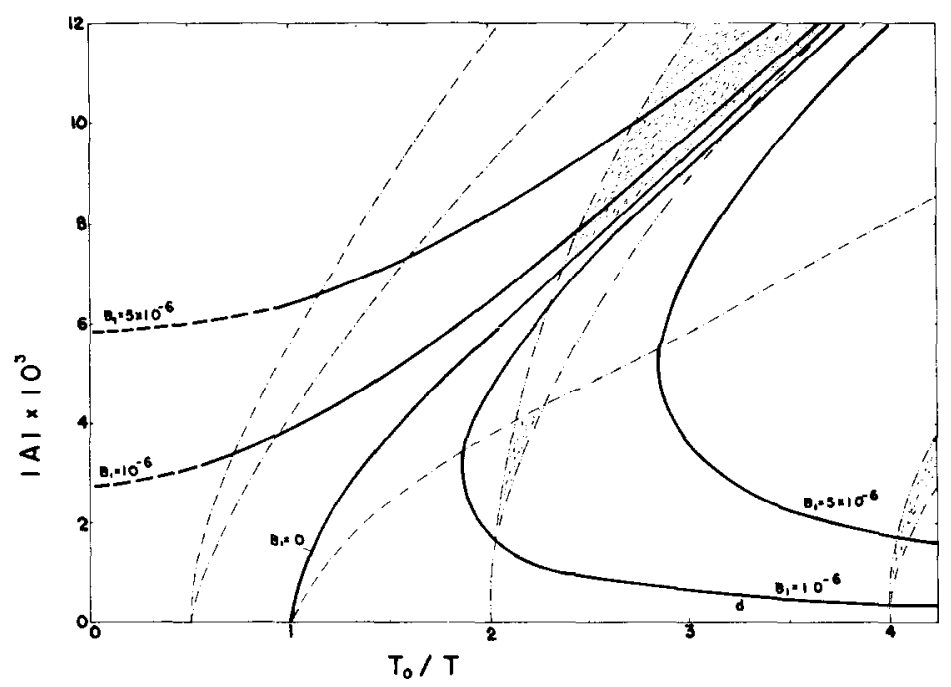

Fig. 4(a). Combined stahility regions for the first and second modes with the first mode forced. $\lambda=0$.

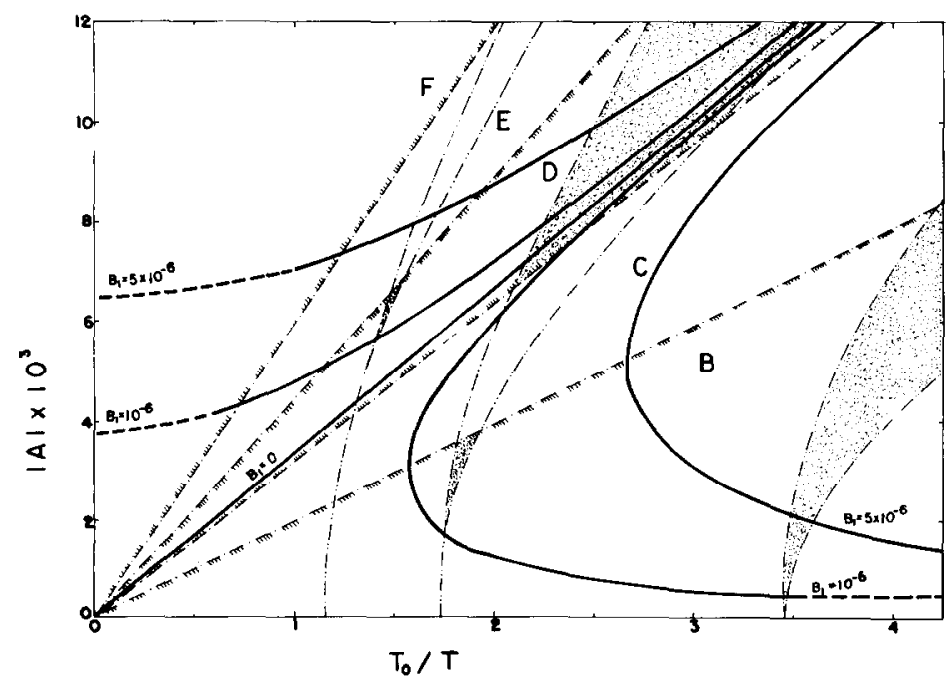

Fig. 4(b). Combined stability regions for the first and second modes with the first mode forced. $\lambda=1$. 
It should be noted that in the dashed portions of the response curves to the left of the last shown stability boundary there are additional narrow regions of instability. A very small amount of damping eliminates these instabilities also.

It should also be noted that the solution, equation (8) requires symmetrical motion

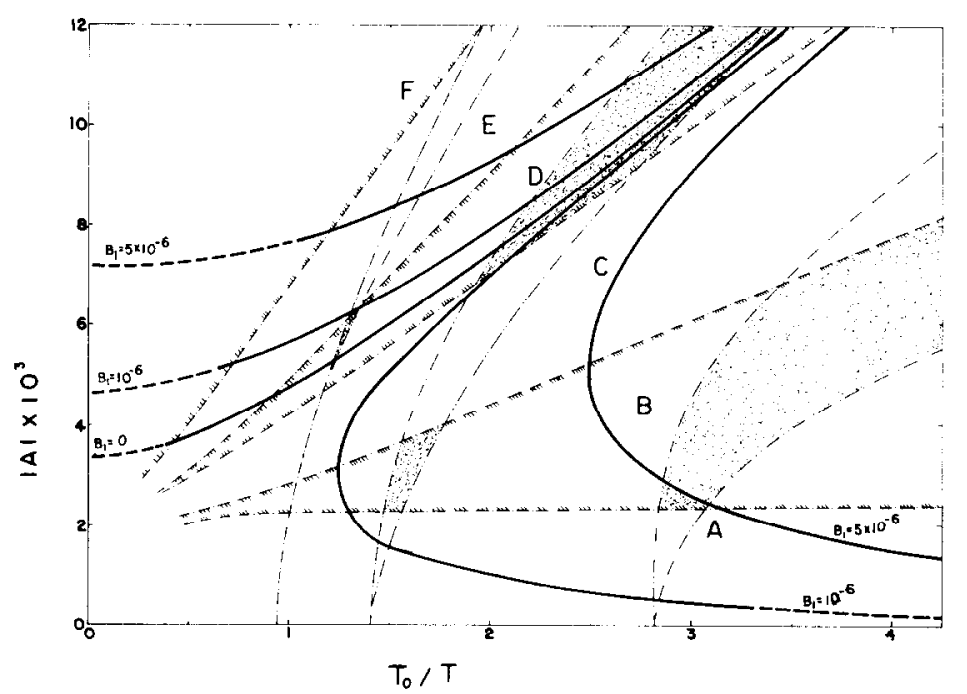

FIG. 4(c). Combined stability regions for the first and second modes with the first mode forced. $\lambda=2$.

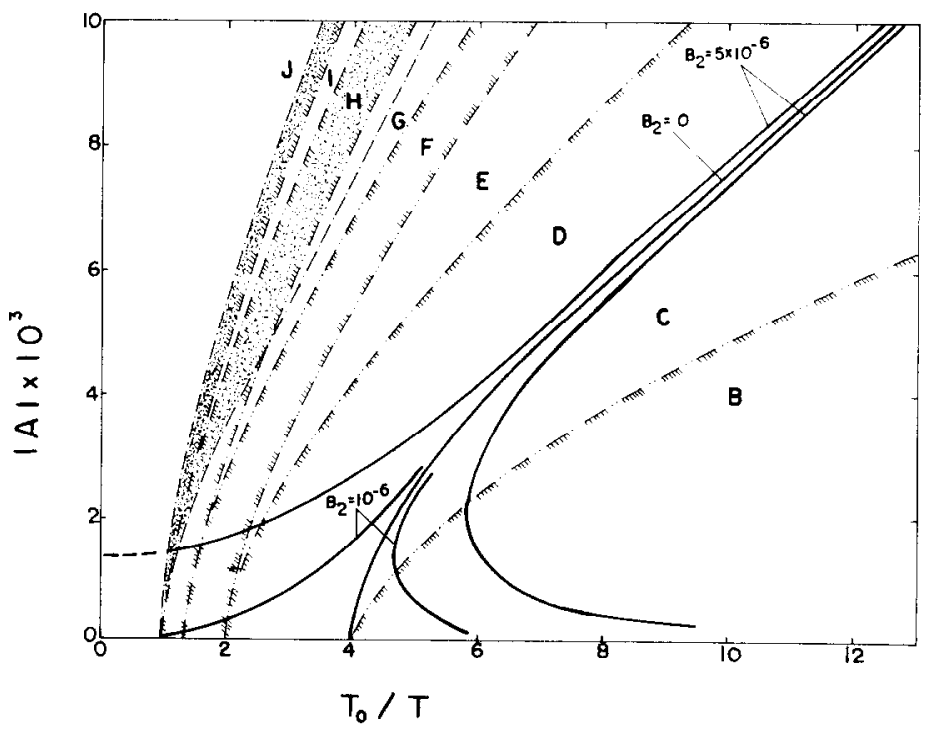

Fig. 5(: $)$. Combined stability regions for the first and second modes with the second mode forced. $\lambda=0$, 
about the flat position. For the buckled case $(\lambda>1)$ another type of motion is possible in which vibration takes place about the buckled position on one side of the flat position. This latter type of motion is not considered here. Therefore in the above it is assumed that the proper conditions exist for exciting the motion.

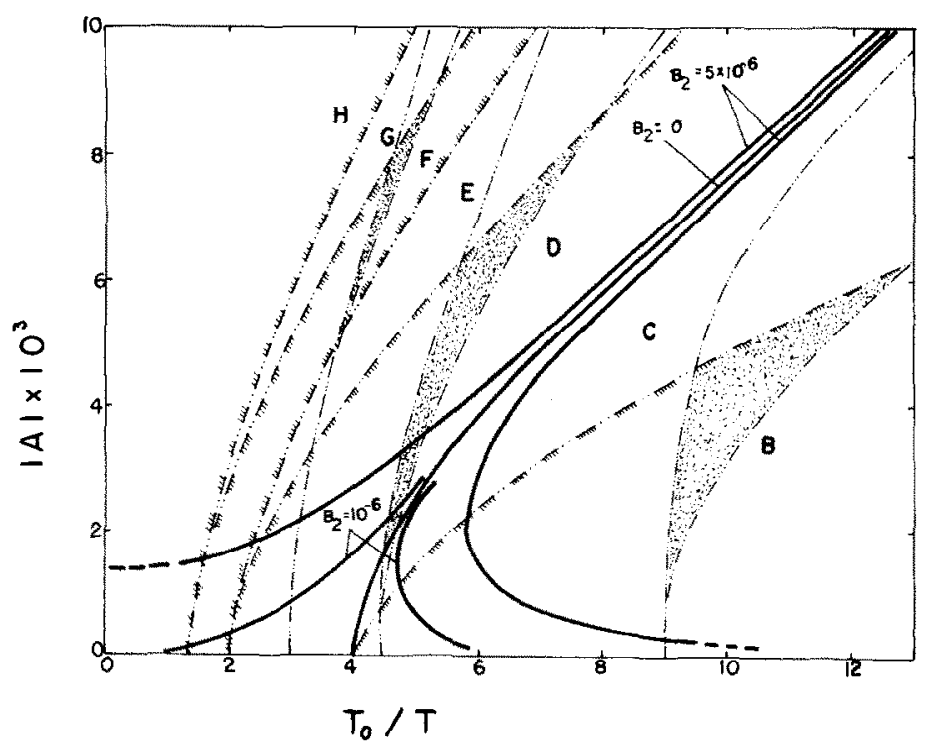

Fiv. 5(b). Combined stability regions for the second and third modes with the second mode forced, $\lambda=0$.

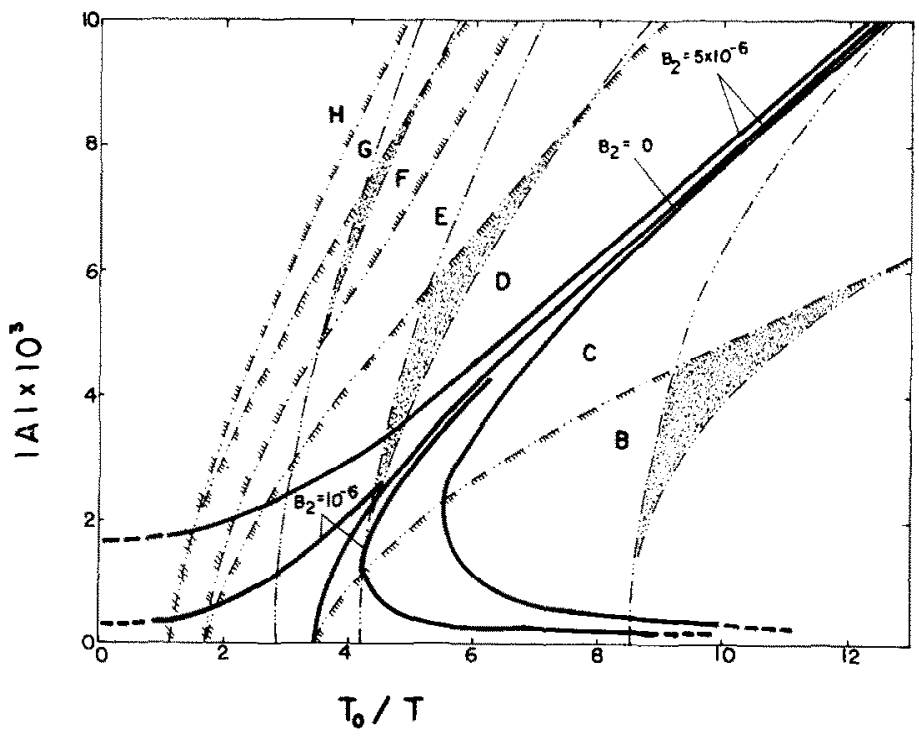

FIG. 5(c). Combined stability regions for the second and third modes with the second mode fored. $\lambda=1$. 


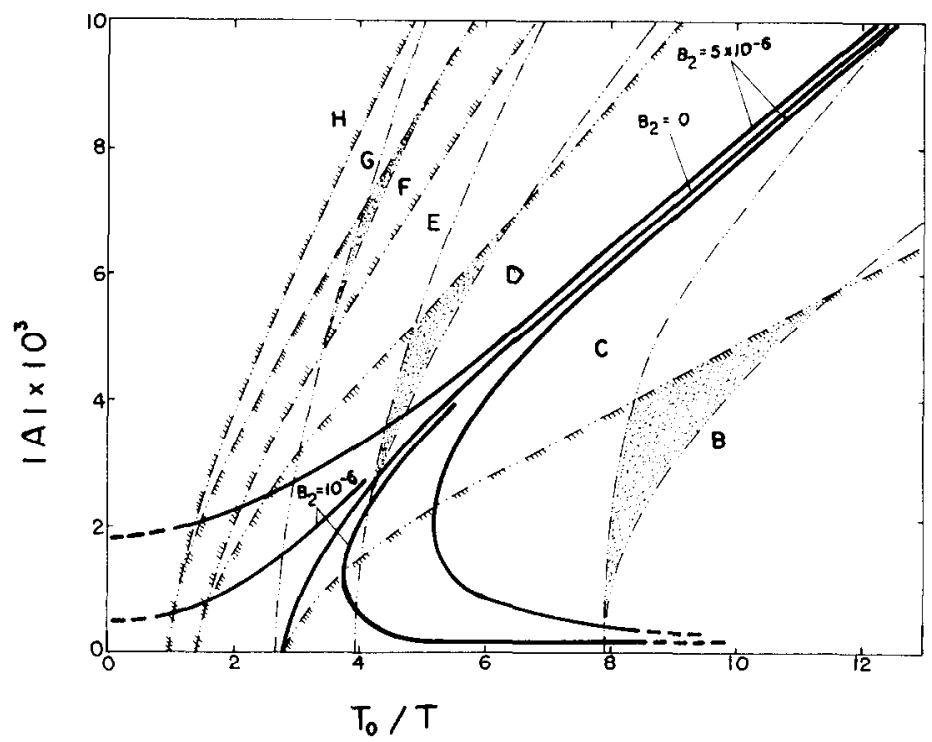

FIG. 5(d). Combined stability regions for the second and third modes with the second mode forced $\lambda=2$.
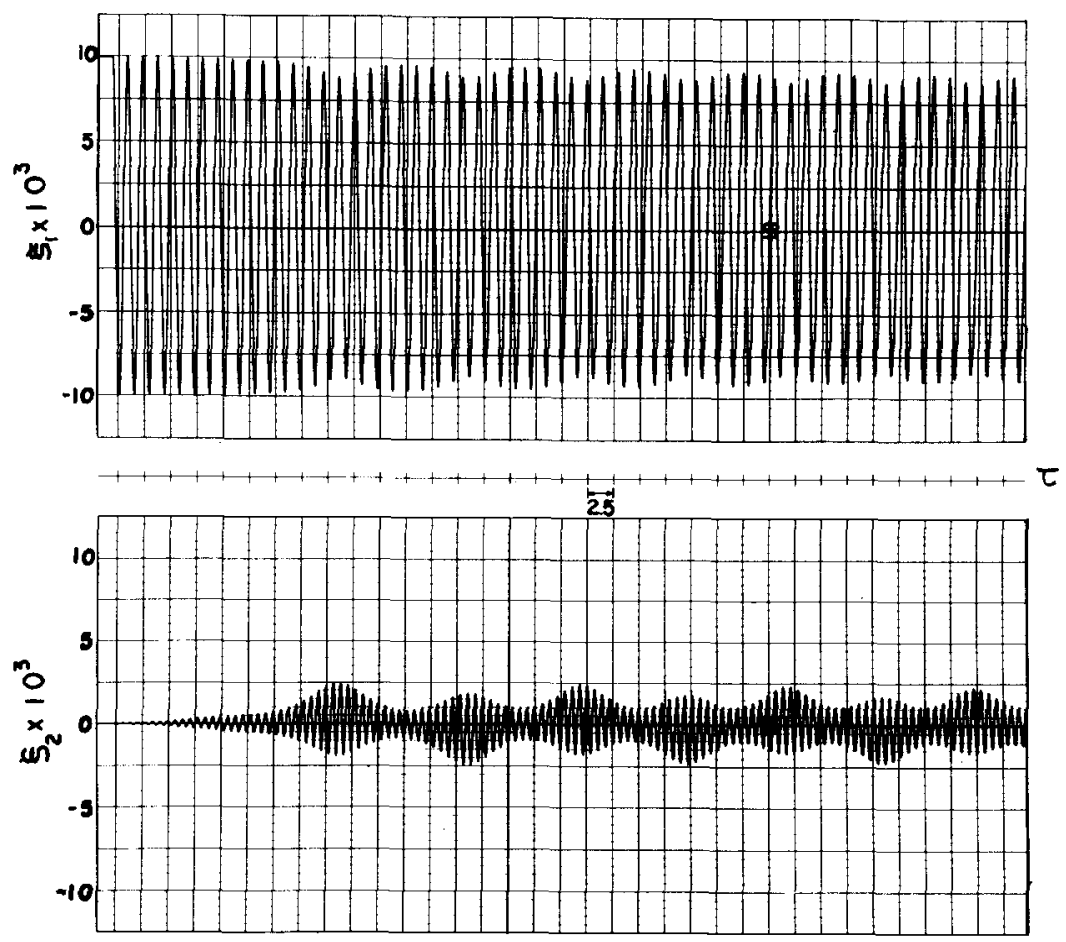

FIG. 6(a). Response corresponding to point $a$ in Fig. 3. 


\section{ANALOG COMPUTER STUDIES}

The equations which led to the response curves presented in Fig. 4(a) were also solved on an analog computer in order to confirm the regions of second mode instability and to examine the nature of the actual response when the second mode is unstable. These studies confirm that second mode instability does exist. They also confirm that a small amount of damping does eliminate instability where the instability regions are narrow.

Points which lie in the main region of second mode instability, such as represented by points $a, b$, and $c$ in Fig. 4(a) identify cases with interesting properties. In Figs. 6(a)-(c) are shown the analog traces for both first and second mode response for initial conditions and applied forcing functions which correspond to points $a, b$, and $c$ in Fig. 3, respectively. In Fig. 6(a) we examine the free motion when an initial displacement is given to the first mode but the second mode is at rest. Note the interchange of energy from the first mode to the second and the subsequent growth of the second mode response.

In Fig. 6(b) we examine the case where the second mode is initially at rest but the first mode is subjected to steady state harmonic forcing. If the second mode were not present the first mode would have a stable steady state response. Once again we have a second mode response and evidence of energy exchange between modes.

In Fig. 6(c) the motion corresponding to point $c$ is recorded with results similar to those
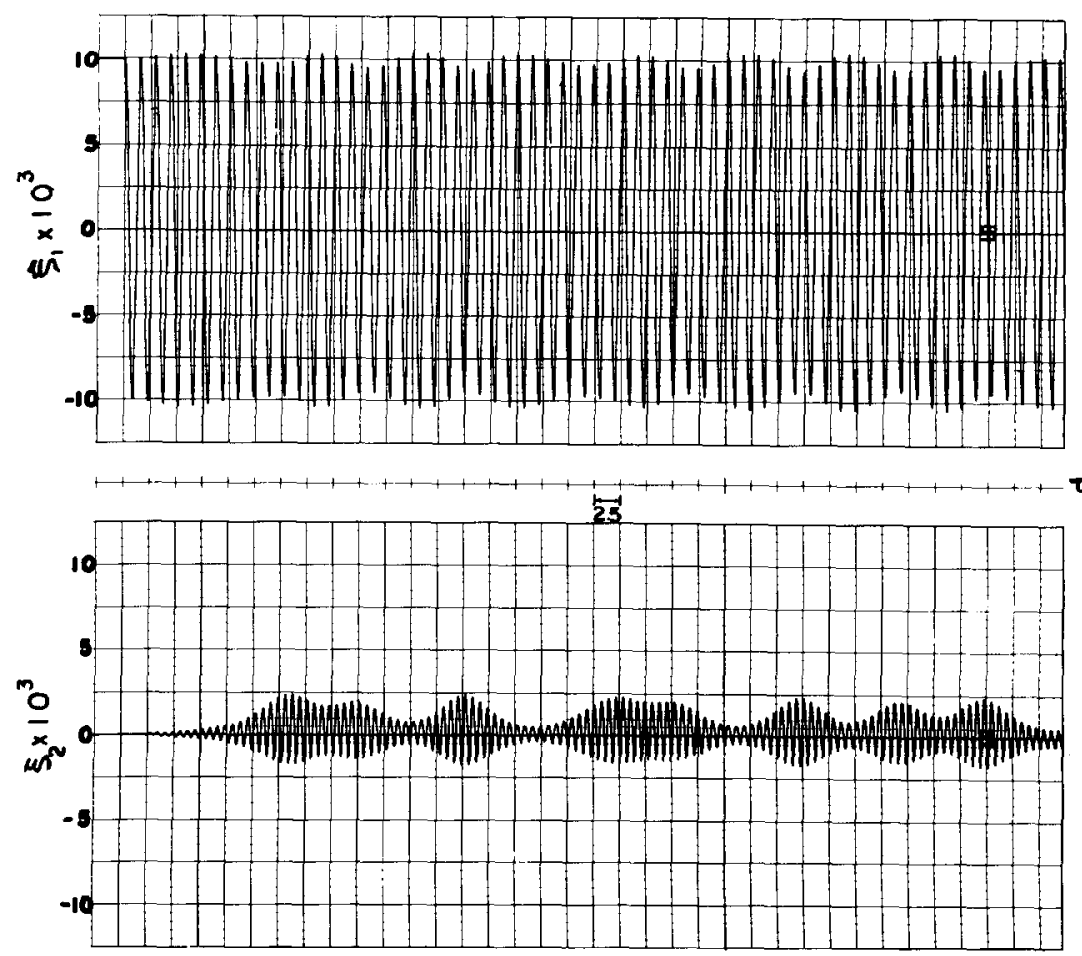

FIG. 6(b). Response corresponding to point $b$ in Fig. 3. 
for point $b$. It is noted that with a very small amount of damping added we observe the jump phenomena [11] and the amplitude changes abruptly to the point $d$ on the lower portion of the curve.

\section{CONCLUSION}

It is concluded that the approximation of single mode response is an over-simplification of large amplitude beam vibration when in a region of higher mode instability. The resulting motion is shown to be different from the usual single mode response.
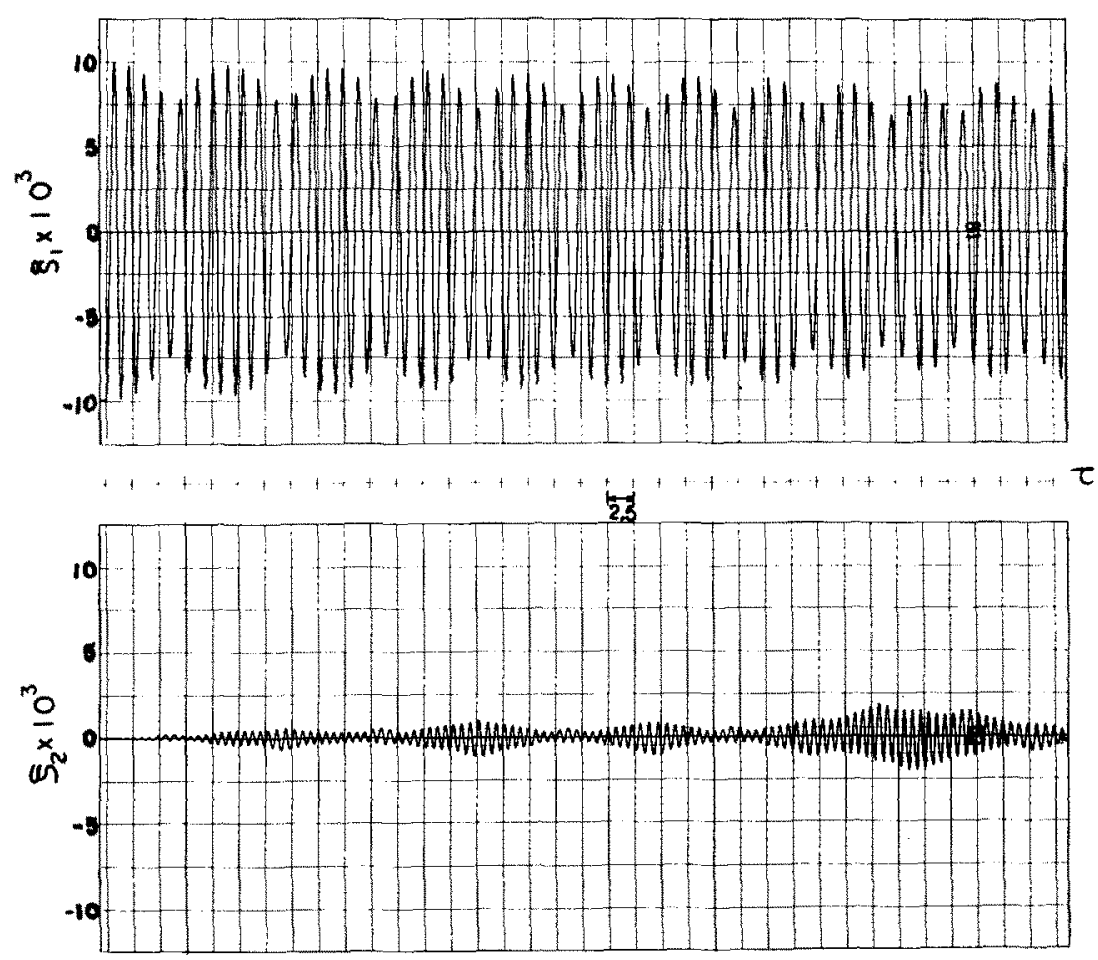

FIG. $6(c)$. Response corresponding to point $c$ in Fig. 3.

Acknowledgement-. The authors wish to thank Mr. Gwo-Bao Min for his help in performing the computations.

\section{REFERENCES}

[1] D. BuRgkeen, Free vibrations of a pin ended column with constant distance between ends. J. appl. Mech. 18 , $135139(1951)$.

[2] P. H. MCDonald, Nonlinear dynamic coupling in a beam vibration. J. appl. Mech. 22, 573 578 (1955).

[3] J. G. EsLEY, Nonlinear deformation of elastic beams, rings, and strings. Applied Mechantes Surveys, pp. 285-290. Spartan (1966).

[4] E. MetTler, Zum Problem der Stabilität erzwingener schwingungen elastischer Körper, Z. angew. Math. Mech. 31, 263264 (1951).

[5] J. G. Fist.fy. Nonlinear vibration of beams and rectangular plates. Z. angew. Math. Phvs. 15, 167-175 (1964). 
[6] R. F. Henry and S. A. ToBiAS, Modes at rest and their stability in coupled non-linear systems. J. Mech. Eng. Sci. 3, 163-173 (1961).

[7] A. O. Gilchrist, The free oscillations of conservative quasilinear systems with two degrees of freedom, Int. J. Mech. Sci. 3, No. 4, 286-311 (1961).

[8] C. J. H. Williams and S. A. ToBias, Forced undamped non-linear vibrations of imperfect circular discs, J. mech. Engng. Sci. 5, 325-335 (1963).

[9] G. J. Efstathiades and C. J. H. Williams, Vibration isolation using non-linear springs. Int. J. mech. Sci. 9. $27-44$ (1967).

[10] N. W. MCLaChlan, Theory and Application of Mathieu Functions. Oxford University Press (1947).

[11] C. HAYASHI, Nonlinear Oscillations in Physical Systems. McGraw-Hill (1964).

(Received 12 February 1969)

Résumé - Le régime permanent à grande amplitude du mouvement forcé d'une poutre en appui simple dont les extrémités sont contraintes de rester séparées par une distance constante est représentée par une série de modes normaux linéaires. On examine la validité de l'hypothèse d'une réponse en mode unique en étudiant la stabilité des modes non forcés lorsqu'un seul mode est forcé. Les équations comprennent les effets d'une charge initiale axiale et on donne des exemples numériques pour les charges axiales dans les deux régions: avant et après flambage. On conclut que l'approximation d'une réponse en mode unique n'est pas toujours valable à cause d'unê instabilité possible des modes supérieurs.

Zusammenfassung--Die erzwungene Bewegung eines einfach unterstützten Trägers mit grosser Amplitude im stationären Zustand, wobei die Entfernung zwischen den beiden Enden fixiert ist, wird mit Hilfe einer Reihe linearer Normalschwingungen dargestellt. Die Gültigkeit der Annahme der Anregung einer einzigen Schwingung wird geprüft, indem die Stabilität der freien Schwingungen untersucht wird, wenn eine einzelne Schwingung erzwungen wird. Die Gleichungen enthalten die Wirkungen einer anfänglichen axialen Last, und numerische Beispiele für axiale Lasten vor und nach erfolgter Durchbiegung werden behandelt. Es wird geschlossen, dass die Näherungsannahme der Anregung einer einzigen Schwingung wegen der möglichen Instabilität höherer Schwingungen nicht immer gültig ist.

Аннотация-Рассматривается возмущенное движение свободно опертой балки при предположении постоянства расстояния между концами балки. Установившееся состояние балки с большими амплитудами описано рядом, составленным из линейных собственных колебаний балки. Справедливоств предположения о том, что балка движется в виде отдельного собственного колебания проверяется путем исследования устойчивости невозмущенных форм колебаний при возмущении рассматриваемой отдельпой формы. Рассматриваемые уравнения учитывают влияние начальной осевой нагрузки. Представлены численные примеры в случеях осевых нагрузок, прикладываемых перед и после того, как произошел продольный 